\title{
Pesticide impacts on predator-prey interactions across two levels of organisation
}

\author{
Jes Jessen Rasmussen ${ }^{\mathrm{a}, *}$, Ulrik Nørum ${ }^{\mathrm{b}}$, Morten Rygaard Jerris ${ }^{\mathrm{b}}$, Peter Wiberg-Larsen ${ }^{\mathrm{a}}$, \\ Esben Astrup Kristensen ${ }^{a}$, Nikolai Friberg ${ }^{a}$ \\ a Aarhus University, Institute of Bioscience, Vejlsøvej 25, 8600 Silkeborg, Denmark \\ b University of Southern Denmark, Campusvej 55, 5230 Odense, Denmark
}

\section{A R T I C L E I N F O}

Article history:

Received 12 March 2013

Received in revised form 20 June 2013

Accepted 21 June 2013

\section{Keywords:}

Pyrethroids

Macroinvertebrates

Predator-prey

Pulse exposure

Species interactions

\begin{abstract}
A B S T R A C T
In this study, we aimed to evaluate the effects of a short pulse exposure of the pyrethroid lambdacyhalothrin (LC) on the predator and anti-predator behaviour of the same species; Gammarus pulex. Predator behaviour, at the level of the individual, was studied in indoor microcosms using video tracking equipment during simultaneous exposure of the predator (G. pulex) and its prey (Leuctra nigra) during $90 \mathrm{~min}$ exposure of $1,6.6$ or $62.1 \mathrm{ng} \mathrm{L}^{-1} \mathrm{LC}$. During an initial $30 \mathrm{~min}$ of exposure, the predator and prey organisms were maintained physically separated, and the actual interaction was studied through the subsequent $60 \mathrm{~min}$ of exposure. The anti-predator behaviour of G. pulex (drift suppression in response to the presence of brown trout) was studied in outdoor stream channels during a 90 min pulse exposure to LC (7.4 or $79.5 \mathrm{ng} \mathrm{L}^{-1}$ ) with, or without, brown trout. Based on survival curves for $L$. nigra we found that the mortality rate for $L$. nigra significantly decreased during exposure to 6.6 and $62.1 \mathrm{ng} \mathrm{L}^{-1} \mathrm{LC}$ $(P<0.05$ and $P<0.001$, respectively). We found no significant effects suggesting that $G$. pulex was repelled by contaminated prey items $(P>0.05)$. We found that the exposure of $G$. pulex to 7.4 and $79.5 \mathrm{ng} \mathrm{L}^{-1}$ LC significantly increased drift (from $\sim 0 \%$ to $\sim 100 \%$ in both treatments; $P<0.001$ ) independent of the presence of brown trout $(P<0.05)$. In other words, the natural anti-predator behaviour of $G$. pulex was overruled by the stress response to LC exposure increasing $G$. pulex predation risk from drift feeding brown trouts. Our results show that the anti-predator and predator behaviour of $G$. pulex were significantly changed during exposure to very low and environmentally realistic LC concentrations and exposure duration. The potential implications for the field scenario are discussed.
\end{abstract}

(c) 2013 Elsevier B.V. All rights reserved.

\section{Introduction}

The increasing contamination of freshwater ecosystems with numerous diffuse source synthetic pesticides is recognised as one of the most important stressors to freshwater ecosystems (Schwarzenbach et al., 2006). Particularly, the use of synthetic pyrethroid insecticides has raised much concern due to their high toxicity to non-target freshwater fauna (Schulz, 2004; Kuivila et al., 2012).

Traditionally, the ecotoxicity of specific chemical compounds is assessed by conducting standardised tests using selected model organisms (daphnia, algae and fish) and toxicity endpoints (i.e. mortality; Rand, 1995). However, effect thresholds for pesticides have been shown to be lower, in terms of changes in the macroinvertebrate community structure, in complex systems like mesocosms (Liess and Beketov, 2011) and natural streams (Schäfer

\footnotetext{
* Corresponding author. Tel.: +45 87158779.

E-mail address: jr@dmu.dk (J.J. Rasmussen).
}

et al., 2012) compared to what can be predicted from single species standard toxicity tests alone (despite the normally applied $100 \times$ safety factor). This may partly be explained by the influence of pesticide exposure on complex mechanisms and species interactions - effects that are not encompassed in single species toxicity tests. Thus, in order to understand pesticide effects at the level of ecosystems, detailed information is required on pesticide induced changes of species interactions incorporating different trophic levels. A specific interaction that can be affected by pesticide exposure is changed interactions between species and their natural predators.

Whereas several studies provide information on pesticide induced changes of predator-prey interactions, most of these studies were conducted using long exposure periods ( $>12 \mathrm{~h}$; e.g. Ballesteros et al., 2009; Englert et al., 2012; Janssens and Stoks, 2012). Since highly hydrophobic compounds like synthetic pyrethroids $\left(\log K_{\mathrm{OW}}>5\right)$ mainly occur in the aqueous form in short time intervals in the field, aquatic biota is exposed to them through the water phase for short periods only (Schulz, 2004). Subsequently, pyrethroids may sorb to particles, e.g. in the sediments providing 
a more chronic exposure route to benthic and epibenthic fauna (e.g. Kuivila et al., 2012). Nevertheless, the use of long term exposure with pyrethroids in the water phase is not realistic and may overestimate the effects of the water phase exposure in the field. Importantly, however, short-term exposure of freshwater macroinvertebrates to synthetic pyrethroids has been shown to induce long-term effects (see e.g. Liess and Schulz, 1996; Rasmussen et al., 2008).

The anti-predator behaviour of macroinvertebrate prey species has been shown to be affected during and after pulse exposure to pyrethroids (e.g. Schulz and Dabrowski, 2001; Reynaldi et al., 2011). The summed effect of pyrethroid exposure on prey populations may increase when the predator is less sensitive to the pesticide as indicated by Bundschuh et al. (2012). Nevertheless, effects of pesticides on populations can increase or decrease depending on the species involved, even when prey species are more tolerant.

The principal aim of this study was to assess the effects of a short-term exposure to the synthetic pyrethroid lambdacyhalothrin (LC) at field-relevant concentrations on the freshwater amphipod Gammarus pulex (L.) in the role as predator and prey. The selection of $G$. pulex as model organism in this study is based on its wide distribution and often dominance in northern European lowland streams and its central role in stream food webs as both predator and prey (MacNeil et al., 1997). The brown trout (Salmo trutta L.) often co-exists with G. pulex and frequently preys upon drifting G. pulex (MacNeil et al., 1997). In consequence, especially large G. pulex are known to suppress drift activity in the presence of trout in order to avoid predation (Friberg et al., 1994). Conversely, G. pulex is very sensitive to pyrethroid exposure with active escape responses (catastrophic drift) at low concentrations, down to $1 \mathrm{ng} \mathrm{L}^{-1}$, of LC (Nørum et al., 2010). The normal suppression of drift activity by G. pulex in the presence of trout may be overruled by pyrethroid exposure, hereby increasing the potential predation success of trout on drifting gammarids. G. pulex is characterised by high feeding plasticity (Kelly et al., 2002) mainly acting as a shredder, but it is also frequently found to prey upon other macroinvertebrate species (MacNeil et al., 1997). However, the stress imposed on gammarids by pyrethroid exposure significantly changes the behaviour of G. pulex (hyperactivity followed by decreased mobility or immobilisation; Nørum et al., 2010), which may affect the interaction between G. pulex and its prey. In addition, pyrethroid exposure may affect prey behaviour prompting additional changes in the predator-prey interactions. We used the stonefly Leuctra nigra, naturally belonging to the prey repertoire of G. pulex (MacNeil et al., 1997), as prey organism. We hypothesised that LC exposure would (1) initiate drift of $G$. pulex irrespective of the presence of trout increasing their proneness to predation by brown trout and (2) negatively influence predation rates of $G$. pulex on the stonefly $L$. nigra.

\section{Materials and methods}

\subsection{Predator-prey interactions in the laboratory}

G. pulex and L. nigra were collected in small Danish streams uncontaminated by pesticides (Lindved River, Funen for G. pulex and an unnamed stream in Velling Forest, Jutland for L. nigra). A few individuals of $G$. pulex were infected by an acanthocephalan parasite, e.g. Pomphorhynchus laevis, as evident by a bright orange line along the dorsal carapace, and since this parasite may alter the behaviour of G. pulex (Lagrue et al., 2007) these individuals were discarded.

The animals were temperature acclimated for 1 day in aerated stream water. G. pulex was acclimated at $15 \pm 1{ }^{\circ} \mathrm{C}$, while $L$. nigra was acclimated at $6 \pm 1^{\circ} \mathrm{C}$ in order to minimise mortality.
Subsequently, the animals were transferred to 10 -L polyethylene aquaria and acclimated for one week in aerated artificial freshwater (AFW) at constant temperature under a $12 \mathrm{~h}$ light: $12 \mathrm{~h}$ dark regime. During the acclimation period the animals were fed ad libitum with leaf litter from the site of collection in order to avoid starvation and lost fitness as confounding factors in the experiment. AFW was used instead of stream water in order to minimise sorption of lambda-cyhalothrin to suspended nanoparticles. The composition of the AFW equalled the ISO 6431 test water of the OECD test guidelines (OECD, 2004). The species specific weight distributions were estimated from size measurements using previously published relations between the length of a morphological unit (length of 1 st thoracic segment and width of head capsule for G. pulex and L. nigra, respectively) and the dry weight of the animals (Iversen and Jessen, 1977; Friberg et al., 2002). The estimated dry weight of G. pulex and L. nigra were $4.29 \pm 0.10 \mathrm{mg}$ and $0.29 \pm 0.01 \mathrm{mg}$, respectively.

On the day prior to the exposure, individual G. pulex were transferred to glass Petri dishes ( $9 \mathrm{~cm}$ in diameter) and acclimated overnight at $15 \pm 1{ }^{\circ} \mathrm{C}$. On the day of exposure LC, dissolved in $10 \mu \mathrm{L}$ of ethanol in $20 \mathrm{~mL}$ of AFW, was added to the Petri dishes (controls were exposed to $10 \mu \mathrm{L}$ of ethanol and in $20 \mathrm{~mL}$ of AFW). The volume of $20 \mathrm{~mL}$ was chosen to ensure rapid mixing, and the liquid was added at a position as far away as possible from the animal. The final concentration of ethanol was $100 \mu \mathrm{LL}^{-1}$, which is in accordance with OECD test guidelines (OECD, 2000). Immediately after the addition of liquid, a polyethylene plastic tube $(2.7 \mathrm{~cm}$ in diameter and open at both ends) was placed in the centre of each Petri dish, and a single $L$. nigra was transferred to the tube. In this way, the predator and the prey were physically separated during the initial $30 \mathrm{~min}$ of LC exposure. Subsequently, the plastic tubes were removed and the predator-prey interaction during a $60 \mathrm{~min}$ observation period of continued exposure was recorded using EthoVision Pro ${ }^{\circledR}$ (Noldus Information Technology, Holland) as described by Nørum et al. (2011). At the end of the experiment water was sampled for determination of LC concentration.

A total of 92 predator-prey pairs were divided into 5 treatment groups: a control group $(n=24)$, three groups exposed to $1 \mathrm{ng} \mathrm{L}^{-1} \quad(n=25), 10 \mathrm{ng} \mathrm{L}^{-1} \quad(n=18)$, and $100 \mathrm{ng} \mathrm{L}^{-1} \quad(n=16)$, and a group where only the $L$. nigra were preexposed to $100 \mathrm{ng} \mathrm{L}^{-1}$ for $30 \mathrm{~min}$ before being transferred to plastic tubes in Petri dishes containing uncontaminated water and unexposed G. pulex $(n=9)$ (all nominal concentrations). This final group was included to test if pre-exposure of the prey would have a repelling effect on G. pulex. In each round of video tracking, 16 predator-prey pairs were observed and the experiment was completed in 4 days.

\subsection{Drift behaviour in stream channels}

The study of drift behaviour was conducted in an outdoor stream channel facility in Lemming, Denmark $\left(9^{\circ} 40^{\prime}, 56^{\circ} 15^{\prime}\right)$ consisting of 12 replicate channels being constantly supplied with uncontaminated groundwater (Supplementary material, Table B1). The individual stream channels were $4 \mathrm{~m}$ long, $10 \mathrm{~cm}$ wide and had a slope of $1 \%$. Each channel was supplied with gravel $(1-3 \mathrm{~cm}$ in diameter) along the first 3 metres (upstream). Moreover, larger stones $(6-8 \mathrm{~cm}$ in diameter) were positioned every $30 \mathrm{~cm}$, and two alder leaves (Alnus glutinosa) were mounted to each stone with cotton threads. The substrate was conditioned in the channels for 7 days prior to the experiment in order to establish microbial communities on substrates and leaves. A drift net was mounted at the downstream end of the channels for collection of drifting animals.

The experimental animals ( $G$. pulex, $n=30$ ) were collected in Lindved River (same locality as G. pulex for video tracking experiments) $24 \mathrm{~h}$ prior to the experiment and were released into the stream channels immediately after collection. Animals drifting out 
of the stream channels within $1 \mathrm{~h}$ after release were reintroduced to the channels immediately. Furthermore, $1 \mathrm{~h}$ before exposure, the animals caught in the drift nets during the night were replaced by fresh individuals (50-60\% of the animals).

We conducted two sets of experiments with or without 2 brown trouts caged in the water supply box (Supplementary material, Fig. B1). In each set of experiments, we used two LC treatments (10 ng L $\mathrm{L}^{-1}$ and $100 \mathrm{ng} \mathrm{L}^{-1}$; nominal concentrations) and controls $(n=4)$. The exposure period was $90 \mathrm{~min}$ and the LC solutions were released directly into each of the stream channels using peristaltic pumps. Water samples from each channel were collected just before terminating exposure ( $90 \mathrm{~min}$ ) for determination of LC concentrations. The channels and substrates were changed between the two sets of experiments (with and without trout) to avoid cross contamination. All experiments were conducted in April 2005. The LC exposures were conducted at $10 \mathrm{AM}$ where background drift of G. pulex is supposed to be minimal (Friberg et al., 1994). However, we did conduct an additional experiment at $10 \mathrm{PM}$, where drift is supposed to be maximal (Friberg et al., 1994). This was done in order to validate the effect of the applied level of trout odour on drift activity during the period of highest natural drift activity for G. pulex (Supplementary material, Fig. B2). During LC exposure, drift nets were emptied every $30 \mathrm{~min}$. All drifted animals were preserved in $96 \%$ ethanol and size distributions were measured.

\subsection{Quantification of $L C$ exposure}

The synthetic pyrethroid lambda-cyhalothrin was applied as analytical standards PESTANAL ${ }^{\circledR}$ (99.8\% purity) and was purchased from Sigma-Aldrich (Selze, Germany). Dilutions of the pesticide were produced just before exposure, and the dilution series were based on $96 \%$ ethanol.

Immediately after collection of each water sample, we added a known concentration of internal standard (IS). The pyrethroid esfenvalerate was applied as internal standard since it has physicochemical properties similar to those of LC. The extraction of LC was conducted on a C18-column (Sep Pak Vac, 6cc, 1 g, C18 cartridges). The column was conditioned with $5 \mathrm{~mL}$ methanol and washed with $5 \mathrm{~mL}$ Milli-Q water. The sample was passed through the column at $20 \mathrm{kPa}$ vacuum and subsequently washed with $5 \mathrm{~mL}$ Milli-Q water and dried for $2 \mathrm{~min}$ at $30-40 \mathrm{kPa}$ vacuum. The LC samples were eluded with $4 \mathrm{~mL}$ methanol and re-concentrated by evaporation and re-dissolved in $0.3 \mathrm{~mL} \mathrm{75 \%} \mathrm{methanol.}$

We used a HPLC-MSD system consisting of a HP Series 1100 HPLC and a G1946A MSD quadropole mass spectrometer equipped with electrospray ionisation. A HPLC-column (C18, $150 \mathrm{~mm} \times 2.1 \mathrm{~mm}$, Phenomenex) with a guard column consisting of the same material was used for LC quantification. Using injected sample volumes of $50 \mu \mathrm{L}$ and column temperature of $25^{\circ} \mathrm{C}$, the flow rate was $0.4 \mathrm{~mL} \mathrm{~min}^{-1}$. We used: $10 \mathrm{mM}$ ammoniumacetate:methanol, 990:10 (v:v) and $10 \mathrm{mM}$ ammoniumacetate:methanol, 10:90 (v:v) as eluates A and B, respectively, and the elution gradient was: (time, \% eluent B: ( 0 min, $75 \%$ ); ( 3 min, $100 \%$ ); (14 min, $100 \%$ ); postrun time: $6 \mathrm{~min}, 25 \%$ eluent B). Mass spectrometer settings were: mode: ESI positive (SIM: $m / z 467$ for LC), (IS SIM: $m / z 437$ ). Drying gas temperature was $350^{\circ} \mathrm{C}$ and flow $10 \mathrm{~L} \mathrm{~min}^{-1}$. Nebulizer pressure was $30 \mathrm{psig}$ and capillary voltage was $3500 \mathrm{~V}$ (Fragmentor: $50 \mathrm{~V}$ ). The standard curve was based on the standards: $0.7,3.5,35.0,70.0$ and $350 \mathrm{ng} \mathrm{L}^{-1}$ injected IS. The limit of quantification of LC was $1 \mathrm{ng} \mathrm{L}^{-1}$ in the water samples. Actual exposure concentrations for the video tracking studies were $62.1 \mathrm{ng} \mathrm{L}^{-1}$ and $6.6 \mathrm{ng} \mathrm{L}^{-1}$ for the $100 \mathrm{ng} \mathrm{L}^{-1}$ and the $10 \mathrm{ng} \mathrm{L}^{-1}$ treatments, respectively, whereas the LC content in the $1 \mathrm{ng} \mathrm{L}^{-1}$ treatments was below the limit for quantification. For the stream channel studies on G. pulex drift activity, the quantified LC concentrations were $79.5 \mathrm{ng} \mathrm{L}^{-1}$ and $7.4 \mathrm{ng} \mathrm{L}^{-1}$ for the $100 \mathrm{ng} \mathrm{L}^{-1}$ and

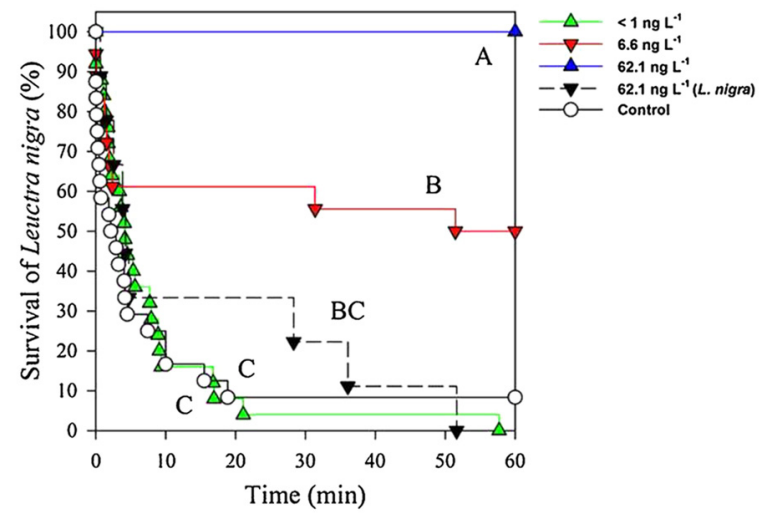

Fig. 1. Survival curves for L. nigra under predation by G. pulex during 60 min exposure to lambda-cyhalothrin (LC). Initially, the predator and the prey were physically separated through the first $30 \mathrm{~min}$ of exposure. Subsequently, the animals were allowed to interact and the predator-prey interaction was recorded through a 60 min observation period of continued exposure. In one treatment group, however, only L. nigra was exposed to LC (indicated in the legend). Capital letters indicate significantly different treatment groups.

the $10 \mathrm{ng} \mathrm{L}^{-1}$ treatments, respectively. For clarity, we use measured concentrations in the remaining parts of the article.

\subsection{Data analysis}

For the predator-prey interactions between G. pulex and L. nigra, the survival curves of the prey in the 5 treatment groups were evaluated using a Kaplan-Meier log-rank survival analysis, followed by a Holm-Sidak adjusted multiple pairwise comparisons test. The statistical analysis was performed using SigmaPlot ${ }^{\circledR} 11.0$ for Windows. A significance level of $\alpha=0.05$ was used.

The drift activity of G. pulex in the presence or absence of trout odour during and after two different LC treatments and controls was analysed using a two-way Analysis of Variance $(n=4)$ with LC treatments and trout odour as effect parameters and summed drift activity as dependent variable. A priori we chose to only analyse summed drift activity after $90 \mathrm{~min}$. Pairwise comparisons were performed using the Bonferroni adjusted Fisher's LSD in the cases of significant ANOVAs. Moreover, we a priori chose to compare the summed drift activity between the control treatments with and without trout odour with the Bonferroni adjusted Fisher's LSD. When necessary, data was transformed to obtain normality and homogeneity of variance. All statistical tests were conducted in SAS Enterprise Guide 4.3 using a significance level of $\alpha=0.05$.

\section{Results}

We found a significant effect of LC treatments on the survival curves for $L$. nigra in the presence of G. pulex (Fig. 1; $P<0.001$ ). The survival curves for the control group and the $<1 \mathrm{ng} \mathrm{L}^{-1} \mathrm{LC}$ treatment were significantly different from the $6.6 \mathrm{ng} \mathrm{L}^{-1}(P=0.02$ and $P=0.007$, respectively) and the $62.1 \mathrm{ng} \mathrm{L}^{-1} \mathrm{LC}$ treatments $(P<0.0001$ for both), although no difference was observed between the control group and the $<1 \mathrm{ng} \mathrm{L}^{-1}$ treatment $(P>0.50)$. Moreover, the survival curves were significantly different between the $6.6 \mathrm{ng} \mathrm{L}^{-1}$ and the $62.1 \mathrm{ng} \mathrm{L}^{-1} \mathrm{LC}$ treatments $(P=0.007)$. Preexposure of $L$. nigra alone to $62.1 \mathrm{ng} \mathrm{L}^{-1} \mathrm{LC}$ for $30 \mathrm{~min}$ prior to the $60 \mathrm{~min}$ predator-prey interaction period resulted in the survival curve being different from the $62.1 \mathrm{ng} \mathrm{L}^{-1}$ treatment $(P<0.0001)$, but not from the control group $(P>0.50)$, the $<1 \mathrm{ng} \mathrm{L}^{-1}(P>0.50)$, nor the $6.6 \mathrm{ng} \mathrm{L}^{-1}(P>0.10)$ treatments.

Representative examples of interactions between $L$. nigra and G. pulex are given in Supplementary material A. In the control group and the $<1 \mathrm{ng} \mathrm{L}^{-1}$ treatment the vast majority of prey were 


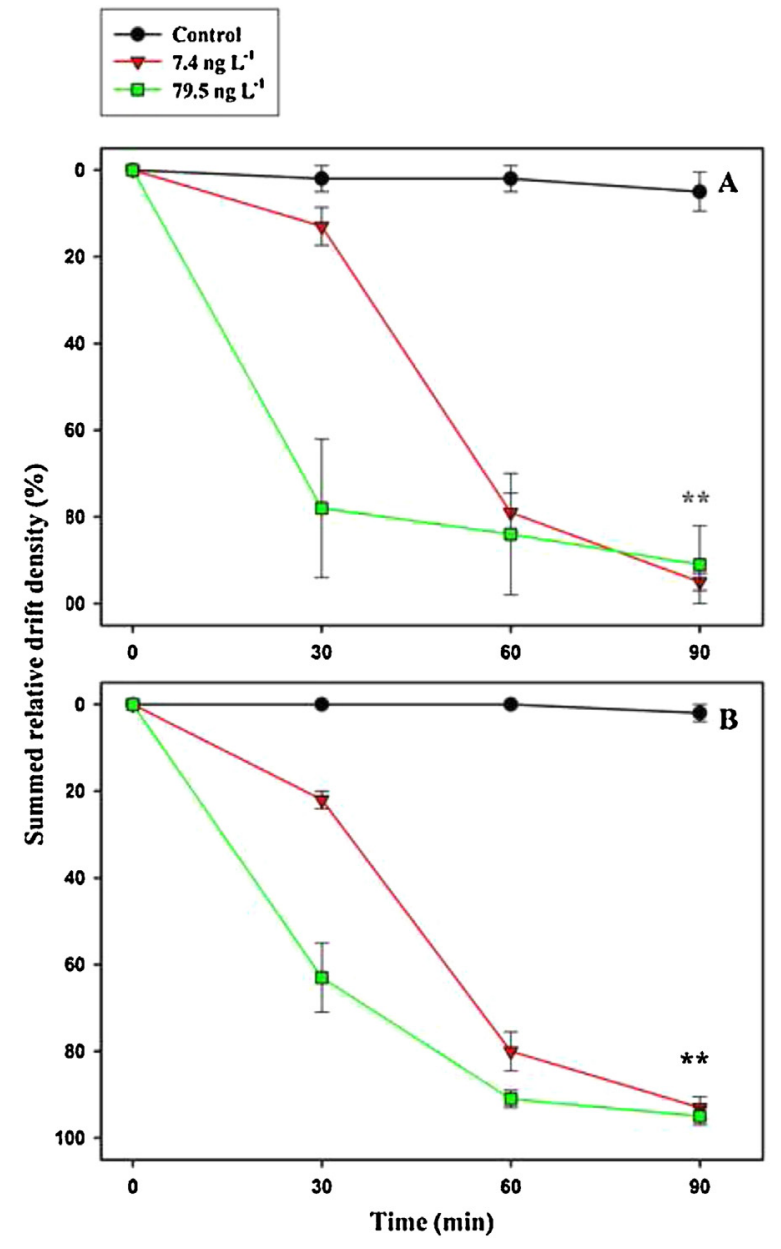

Fig. 2. Percentage drifted $G$. pulex as a function of time from initiated lambdacyhalothrin (LC) exposure $(n=4)$ in the absence (A) or presence (B) of trout odour. The LC exposure was terminated after $90 \mathrm{~min}$. Error bars represent standard error of the mean. Asterisks indicate significant differences compared to controls after 90 $\left({ }^{* *} P<0.001\right)$.

caught within a few minutes, mostly at the first encounter with the predator. G. pulex then typically spent 35-40 min on full prey consumption. When feeding was completed, G. pulex resumed locomotory behaviour. At $6.6 \mathrm{ng} \mathrm{L}^{-1}$ the variability in predatory behaviour increased. All G. pulex in this treatment displayed increased locomotory behaviour and although some $L$. nigra were caught and efficiently consumed, $50 \%$ ( 9 of 18 ) of the $L$. nigra were left untouched at the end of the $60 \mathrm{~min}$ interaction despite several encounters. Moreover, the time spent feeding varied highly and was often disrupted more quickly than in controls. At $62.1 \mathrm{ng} \mathrm{L}^{-1}$ all G. pulex were markedly hyperactive and the prey, L. nigra, was ignored completely despite repeated encounters.

We found a significant effect of LC treatment on the summed drift activity of $G$. pulex immediately after the $90 \mathrm{~min}$ LC exposure (Fig. $2 ; P<0.001$ ). There was no significant effect of trout odour, or interaction between trout odour and LC, after $90 \mathrm{~min}$ LC exposure (two-way ANOVA, $P>0.05$ ). Moreover, the drift activity of $G$. pulex in the control treatments with and without trout odour was not significant $(P>0.05)$. However, the summed drift activity after the $90 \mathrm{~min}$ LC exposure was significantly increased in the $7.4 \mathrm{ng} \mathrm{L}^{-1}$ treatments $(P<0.001)$ and the $79.5 \mathrm{ng} \mathrm{L}^{-1}$ treatments $(P<0.001)$. Additional drift experiments conducted during night with and without trout odour showed that the drift activity of G. pulex was significantly reduced in the presence of trout odour during this normal active drift period (Supplementary material, Fig. B2; $P<0.001)$.

\section{Discussion}

During exposure to sublethal concentrations of LC the predator-prey interactions between G. pulex and L. nigra were significantly altered. The relative frequency of successful predation by G. pulex on L. nigra decreased from nearly $100 \%$ in the control and the $<1 \mathrm{ng} \mathrm{L}^{-1}$ treatments to approximately $50 \%$ in the $6.6 \mathrm{ng} \mathrm{L}^{-1}$ treatment, and no predation was observed in the $62.1 \mathrm{ng} \mathrm{L}^{-1}$ treatment during the $60 \mathrm{~min}$ observation period. These findings probably reflect an increased stress response of G. pulex to increasing concentrations of LC prompting behavioural hyperactivity that overrules the natural instinct of catching the prey. Nørum et al. (2010) showed that the time for offset of hyperactivity for G. pulex in the video tracking arenas correspond to the offset of drift in outdoor experimental stream channels. In fact, Nørum et al. (2010) showed that a pulse exposure of $10 \mathrm{ng} \mathrm{L}^{-1} \mathrm{LC}$ prompted active drift of all G. pulex in stream channels within $90 \mathrm{~min}$. This additionally suggests that the $50 \%$ predation success observed in our study in the $6.6 \mathrm{ng} \mathrm{L}^{-1}$ treatment probably reflects the artificially promoted encounters of predator and prey organisms in the video tracking arena. We suggest that the $6.6 \mathrm{ng} \mathrm{L}^{-1}$ treatment was not fully sufficient for overruling the natural instinct of G. pulex to catch its prey when encountered. Supported by Nørum et al. (2010), we also observed hyperactivity in the $<1 \mathrm{ng} \mathrm{L}^{-1} \mathrm{LC}$ treatment, but the increased stress response in $<1 \mathrm{ng} \mathrm{L}^{-1}$ treatments was not sufficiently strong to significantly suppress natural foraging behaviour of G. pulex.

The pre-exposure of $L$. nigra did not significantly change the predatory activity by unexposed $G$. pulex suggesting that there was no indirect repelling effect through the contamination of prey items which supports the findings of Reynaldi et al. (2011) and Janssens and Stoks (2012). However, through visual inspection it was apparent that a few of the pre-exposed $L$. nigra remained undetected comparatively longer than in the control group or the $<1 \mathrm{ng} \mathrm{L}^{-1}$ treatment. These L. nigra were immobilised by the LC pre-exposure suggesting that pressure waves in the water caused by movement of the L. nigra to some extent may be used by G. pulex to support the detection of prey items. Interestingly, Lauridsen et al. (2006) and Rasmussen et al. (2012) reported that gammarids foraging on leaf material pre-exposed to pyrethroid insecticides showed reduced shredding activity through 7-26 days post-exposure due to probably a repelling effect of contaminated leaves. Since gammarids prefer food items with high nutritional value (such as other macroinvertebrates; Bundschuh et al., 2011), our findings could imply that the contamination of high quality food items with pyrethroid insecticides may not prompt a reduction in G. pulex ingestion rates similar to what has been observed for lower quality food items such as leaves. More research is needed to explore the mechanisms behind these observations.

The applied test organisms in our study have comparable sensitivities to pyrethroids (Nørum et al., 2010). However, considering that the physiological sensitivity of macroinvertebrate species to pyrethroids range several orders of magnitudes (Wogram and Liess, 2001 ), the responses in predator-prey interactions of other species strongly depend on the sensitivities of the predator and the prey organisms.

Due to high $\log K_{\mathrm{OW}}$ of pyrethroids, the active ingredients are expected to be rapidly taken up by freshwater macroinvertebrates (Tang and Siegfried, 1995), and several authors have showed long term effects of short pulse exposures to pyrethroids using functional (Rasmussen et al., 2008) and life-cycle endpoints (Liess and Schulz, 1996; Schulz and Liess, 2000,2001). Moreover, Reynaldi 
et al. (2011) found no effects of a $1 \mathrm{~h}$ pulse of fenvalerate on the predator-prey interactions of Notonecta glauca and Culex pipiens without applying a postexposure observation period. Since applying postexposure observation periods may increase the response sensitivity of predator-prey interactions to pyrethroid exposure we suggest that the true effect thresholds in our study may in fact be lower than our results suggest.

We found that the exposure with sublethal concentrations of LC significantly increased the drift activity of G. pulex during a $90 \mathrm{~min}$ exposure period, indicating that LC exposure prompted immediate active or passive drift initiation in accordance with previous findings (Liess, 1994; Heckmann and Friberg, 2005). More importantly, we found that the increased drift rates as response to LC exposure was maintained irrespective of the presence of trout. Moreover, from night drift experiments we found that the applied level of trout odour in the experimental streams were sufficient to significantly suppress the natural drift activity of $G$. pulex (Supplementary material, Fig. B2). Thus, we conclude that the natural behavioural response of G. pulex to the presence of trout (decreasing their drift activity; Friberg et al., 1994) was overruled by the response to LC exposure. In fact, virtually all G. pulex drifted out of the stream mesocosms in both LC treatments suggesting that significant effect concentrations are below the lowest concentration (7.4 $\left.\mathrm{ng} \mathrm{L}^{-1}\right)$ applied in our study. Since the behavioural adaptation of $G$. pulex to the presence of trout is probably an active anti-predator response minimising the risk of predation, we suggest that the increase in drift activity prompted by LC exposure can increase the predation rate of brown trout on G. pulex in the field. Resident trouts in streams receiving pyrethroid insecticides are also exposed to the pesticides, which may influence their predatory behaviour. However, the $24 \mathrm{~h}$ LC50 for young rainbow trouts (Oncorhychus mykiss) exposed to LC is $41.7 \mu \mathrm{g} \mathrm{L}^{-1}$ (Kucukbay et al., 2009) and it is therefore highly unlikely that short pulses of LC, with concentrations ranging from 0.01 to $0.1 \mu \mathrm{g} \mathrm{L}^{-1}$, induce significant behavioural changes to the taxonomically related brown trout. Moreover, Schulz and Dabrowski (2001) showed that the predation success of a drift-feeding fish (Galaxias zebratus) on mayfly nymphs (Genus: Baetis) increased significantly during a short pulse exposure to another synthetic pyrethroid; fenvalerate $\left(0.2 \mu \mathrm{g} \mathrm{L}^{-1}\right)$, because the mayflies displayed decreased ability to maintain a fully coordinated swimming behaviour. A similar effect may occur in $G$. pulex due to its high sensitivity to pyrethroid insecticides which may further increase the success rate of trout predation on G. pulex during pyrethroid exposure.

Our results show that the natural predator and predatoravoidance behaviour of $G$. pulex is overruled by stress responses to short pulses of low and environmentally realistic concentrations of the synthetic pyrethroid lambda-cyhalothrin (e.g. Feo et al., 2010; Weston and Lydy, 2012). Considering the pivotal role of G. pulex in stream ecosystems, the observed changes of the predator and predator-avoidance behaviour during LC exposure could influence the population density of G. pulex and their role in the food web. Surely, a key question when using a mesocosm set-up with limited complexity is to what extent these artificial conditions mimic natural and more complex systems. However, our findings add some mechanistic understanding of how species interactions can be modified by pyrethroid exposure and, more importantly, how sensitive such endpoints can be. In addition, our study also provides some insight into the reasons why field-based macroinvertebrate community endpoints are more sensitive than what could be expected from single species standard ecotoxicity tests alone (even though a 100 fold safety margin is maintained; Schäfer et al., 2012).

Overall, effects of environmentally realistic pesticide exposure on predator-prey interactions have received limited attention in freshwater ecotoxicology, but our, and recent studies of other authors (e.g. Bundschuh et al., 2012; Englert et al., 2012; Pestana et al., 2009; Relyea and Hoverman, 2006), document the urgent need for more research with long-term endpoints and more complex set-ups in order to comprehend the potential effects of pesticides across different levels of organisation with the ecosystems.

\section{Acknowledgements}

We thank Vibeke Eriksen, Bente Frost Holbech and Birthe Christensen, Institute of Biology, University of Southern Denmark, for technical assistance. Moreover, we are thankful for the comments of three anonymous reviewers that helped improve the manuscript. This work was supported by a grant from the Danish Environmental Protection Agency.

\section{Appendix A. Supplementary data}

Supplementary data associated with this article can be found, in the online version, at http://dx.doi.org/10.1016/ j.aquatox.2013.06.019.

\section{References}

Ballesteros, M.L., Durando, P.E., Nores, M.L., Diaz, M.P., Bistoni, M.A., Wunderlin, D.A., 2009. Endosulfan induces changes in spontaneous swimming activity and acetylcholinesterase activity of Jenynsia multidentata (Anablepidae, Cyprinodontiformes). Environmental Pollution 157, 1573-1580.

Bundschuh, M., Appeltauer, A., Dabrunz, A., Schulz, R., 2012. Combined effect of invertebrate predation and sublethal pesticide exposure on the behavior and survival of asellus aquaticus (Crustacea; Isopoda). Archives of Environment Contamination and Toxicology 63, 77-85.

Bundschuh, M., Zubrod, J.P., Kosol, S., Maltby, L., Stang, C., Duester, L., Schulz, R., 2011. Fungal composition on leaves explains pollutant-mediated indirect effects on amphipod feeding. Aquatic Toxicology 104, 32-37.

Englert, D., Bundschuh, M., Schulz, R., 2012. Thiacloprid affects trophic interaction between gammarids and mayflies. Environmental Pollution 167, 41-46.

Feo, M.L., Ginebreda, A., Eljarrat, E., Barcelo, D., 2010. Presence of pyrethroid pesticides in water and sediments of Ebro River Delta. Journal of Hydrology 393, 156-162.

Friberg, N., Andersen, T.H., Hansen, H.O., Iversen, T.M., Jacobsen, D., Krojgaard, L. Larsen, S.E., 1994. The effect of brown trout (Salmo trutta L.) on stream macroinvertebrate drift, with special reference to Gammarus pulex L. Hydrobiologia 294 $105-110$.

Friberg, N., Larsen, A.D., Rodkjaer, A., Thomsen, A.G., 2002. Shredder guilds in three Danish forest streams contrasting in forest type. Archiv fur Hydrobiologie 153 197-215.

Heckmann, L.H., Friberg, N., 2005. Macroinvertebrate community response to pulse exposure with the insecticide lambda-cyhalothrin using in-stream mesocosms. Environmental Toxicology and Chemistry 24, 582-590.

Iversen, T.M., Jessen, J., 1977. Life-cycle, drift and production of Gammarus pulex L. (Amphipoda) in a Danish spring. Freshwater Biology 7, 287-296.

Janssens, L., Stoks, R., 2012. How does a pesticide pulse increase vulnerability to predation? Combined effects on behavioral antipredator traits and escape swimming. Aquatic Toxicology 110, 91-98.

Kelly, D.W., Dick, J.T.A., Montgomery, W.I., 2002. The functional role of Gammarus (Crustacea, Amphipoda): shredders, predators, or both? Hydrobiologia 485, 199-203.

Kucukbay, F.Z., Dorucu, M., Yazlak, H., 2009. Acute toxicity of synthetic pyretroid cypermethrin to the young rainbow trout (Oncorhychus mykiss Walbaum, 1792). Asian Journal of Chemistry 21, 1801-1806.

Kuivila, K.M., Hladik, M.L., Ingersoll, C.G., Kemble, N.E., Moran, P.W., Calhoun, D.L., Nowell, L.H., Gilliom, R.J., 2012. Occurrence and potential sources of pyrethroid insecticides in stream sediments from seven U.S. metropolitan areas. Environmental Science and Technology 46, 4297-4303.

Lagrue, C., Kaldonski, N., Perrot-Minnot, M.J., Motreuil, B., Bollache, L., 2007. Modification of hosts' behavior by a parasite: field evidence for adaptive manipulation. Ecology 88, 2839-2847.

Lauridsen, R.B., Kronvang, B., Friberg, N., 2006. Occurrence of sediment-bound pyrethroids in Danish streams and their impact on ecosystem function. Water, Air, and Soil Pollution 6, 423-432.

Liess, M., 1994. Pesticide impact on macroinvertebrate communities of running waters in agricultural ecosystems. In: Sladeckova, A. (Ed.), Proceedings of the International Association of Theoretical and Applied Limnology, vol. 25, Pt 4. , pp. 2060-2062

Liess, M., Beketov, M., 2011. Traits and stress: keys to identify community effects of low levels of toxicants in test systems. Ecotoxicology 20,1328-1340. 
Liess, M., Schulz, R., 1996. Chronic effects of short-term contamination with the pyrethroid insecticide fenvalerate on the caddisfly Limnephilus lunatus. Hydrobiologia 324, 99-106.

MacNeil, C., Dick, J.T., Elwood, R.W., 1997. The trophic ecology of freshwater Gammarus spp. (Crustacea: Amphipoda): problems and perspectives concerning the functional feeding group concept. Biological Reviews Cambridge Philosophical Society $72,349-364$

Nørum, U., Frederiksen, M.A.T., Bjerregaard, P., 2011. Locomotor behaviour in the freshwater amphipod Gammarus pulex exposed to the pyrethroid cypermethrin. Chemistry and Ecology 27, 1-9.

Nørum, U., Friberg, N., Jensen, M., Pedersen, J., Bjerregaard, P., 2010. Behavioural changes in three species of freshwater macroinvertebrates exposed to the pyrethroid lambda-cyhalothrin: laboratory and stream microcosm studies. Aquatic Toxicology 98, 328-335.

OECD, 2000. Guidance Document on Aquatic Toxicity Testing of Difficult Substances and Mixtures, OECD Environment Health and Safety Publications - Series on Testing and Assessment No. 23. OECD, Paris.

OECD, 2004. Daphnia sp., acute immobilisation test and reproduction test, OECD guidelines for testing of chemicals, No. 202. OECD, Paris.

Pestana, J.L.T., Loureiro, S., Baird, D.J., Soares, A.M.V.M., 2009. Fear and loathing in the benthos: responses of aquatic insect larvae to the pesticide imidacloprid in the presence of chemical signals of predation risk. Aquatic Toxicology 93, 138-149.

Rand, G.M., 1995. Fundamentals of Aquatic Ecotoxicology: Effects, Environmental Fate and Risk Assessment, 2nd ed. Taylor \& Francis, Washington, DC.

Rasmussen, J.J., Friberg, N., Larsen, S.E., 2008. Impact of lambda-cyhalothrin on a macroinvertebrate assemblage in outdoor experimental channels: implications for ecosystem functioning. Aquatic Toxicology 90, 228-234.

Rasmussen, J.J., Monberg, R.J., Baattrup-Pedersen, A., Cedergreen, N., Wiberg-Larsen, P., Strobel, B.W., Kronvang, B., 2012. Effects of a triazole fungicide and a pyrethroid insecticide on the decomposition of leaves in the presence or absence of macroinvertebrate shredders. Aquatic Toxicology 118/119, 54-61.
Relyea, R., Hoverman, J., 2006. Assessing the ecology in ecotoxicology: a review and synthesis in freshwater systems. Ecology Letters 9, 1157-1171.

Reynaldi, S., Meiser, M., Liess, M., 2011. Effects of the pyrethroid fenvalerate on the alarm response and on the vulnerability of the mosquito larva Culex pipiens molestus to the predator Notonecta glauca. Aquatic Toxicology 104, 56-60.

Schulz, R., 2004. Field studies on exposure, effects, and risk mitigation of aquatic nonpoint-source insecticide pollution: a review. Journal of Environment Quality 33, 419-448.

Schulz, R., Dabrowski, J.M., 2001. Combined effects of predatory fish and sublethal pesticide contamination on the behavior and mortality of mayfly nymphs. Environmental Toxicology and Chemistry 20, 2537-2543.

Schulz, R., Liess, M., 2000. Toxicity of fenvalerate to caddisfly larvae: chronic effects of 1-vs. 10-h pulse-exposure with constant doses. Chemosphere 41, 1511-1517.

Schulz, R., Liess, M., 2001. Toxicity of aqueous-phase and suspended particleassociated fenvalerate: Chronic effects after pulse-dosed exposure of Limnephilus lunatus (Trichoptera). Environmental Toxicology and Chemistry 20, 185-190.

Schwarzenbach, R.P., Escher, B.I., Fenner, K., Hofstetter, T.B., Johnson, C.A., von Gunten, U., Wehrli, B., 2006. The challenge of micropollutants in aquatic systems. Science 313, 1072-1077.

Schäfer, R.B., Von der Ohe, P.C., Rasmussen, J.J., Kefford, B., Beketov, M., Schulz, R., Liess, M., 2012. Thresholds for the effects of pesticides on invertebrate communities and leaf breakdown in stream ecosystems. Environmental Science and Technology 46, 5134-5142.

Tang, J.X., Siegfried, B.D., 1995. Comparative uptake of a pyrethroid and organophosphate insecticide by selected aquatic insects. Bulletin of Environment Contamination and Toxicology 55, 130-135.

Weston, D.P., Lydy, M.J., 2012. Stormwater input of pyrethroid insecticides to an urban river. Environmental Toxicology and Chemistry 31, 1579-1586.

Wogram, J., Liess, M., 2001. Rank ordering of macroinvertebrate species sensitivity to toxic compounds by comparison with that of Daphnia magna. Bulletin of Environment Contamination and Toxicology 67, 360-367. 